\title{
CONSTRUCTIONS, PROOFS AND THE MEANING OF LOGICAL CONSTANTS*
}

\begin{abstract}
There are cases where we mix two or more exact concepts in one intuitive concept and then we seem to arrive at paradoxical results. Hao Wang.
\end{abstract}

During the last decade both mathematicians and philosophers have been interested in the development of various theories of constructions. The study of these theories has been prompted by at least three sorts of considerations. The first theories were proposed by Kreisel around 1960 as a means of formalizing the intended interpreation for the intuitionistic logical constants as presented in Heyting's Introduction from 1956. Here, in Kreisel's version, the relation

$$
\text { construction } c \text { proves proposition } \boldsymbol{A}
$$

was given a step-wise analysis according to the complexity of $A$, in much the same way as the truth-tables provide such an analysis in the classical case. The main mathematical effort, secondly, has been concentrated on finding suitable formal systems in which to formalize the bulk of constructive mathematics as set out in a well-known book by Bishop. Theories of constructions have here been used to analyze the extra information carried in the constructive reading of mathematical statements. On the other hand, finally, philosophers have mainly been interested in the systematic aspects of the relation

\section{$c$ proves $A$}

and the extent to which it can serve as a key-concept in a "theory of meaning", somewhat along the lines of Davidson's use of Tarski's truthdefinitions for a similar purpose.

The two debates - mathematical and philisophical - have been carried on in parallel. On the mathematical side some (as I see them) quite basic distinctions of a philosophical nature have been neglected, whereas the 
philosophers sometimes simply have taken over the technical frameworks used by the mathematicians without questioning the underlying philosophical motivation.

In the present paper I wish to review some work on Heyting's idea of treating mathematical propositions as expressing intentions towards (proof) constructions. My interest in this area stems from tutorials with Per MartinLöf in 1975 and I have continued to learn from him through many conversations since then. I am also indebted to Professors Scott and Kreisel for many conversations and stimulating correspondence on the topic of the present paper.

\section{TIIE KREISEL FORMALIZATION OF HEYTING'S EXPLANATIONS}

The most well-known of Heyting's discussions can be found in his (1956, pp. 96-7):

\section{Interpretation of the signs.}

The conjunction gives no difficulty. $p \wedge q$ can be asserted if and only if both of $p$ and $q$ be asserted.

...

$p \vee q$ can be asserted if and only if at least one of the propositions $p$ and $q$ can be asserted.

The negation is the strong mathematical negation ... we remember that a mathematical proposition $p$ always demands a mathematical construction with certain given properties; it can be asserted as soon as such a construction has been carried out. We say in this case that construction proves the proposition $p$ and call it a proof of $p$. We also, for the sake of brevity, denote by $p$ any construction which is intended by the proposition $p$. Then $\neg p$ can be asserted if and only if we possess a construction which from the supposition that a construction $p$ were carried out, leads to a contradiction. ...

The implication $p \rightarrow q$ can be asserted, if and only if we possess a construction $r$, which, joined to any construction proving $p$ (supposing the latter be effected), would automatically effect a construction proving $q$.

Kreisel (1962) took the above explanations of Heyting as a starting point in his attempt "to set up a formal system, called 'abstract theory of constructions' for the basic notions mentioned above, in terms of which the formal rules of Heyting's predicate calculuc can be interpreted." The basic notions concerned were "construction (constructive function)" and "constructive proof (of equality between two constructions)." The explanations are then to be incorporated in the theory along the following lines: 
The sense of a mathematical assertion denoted by a linguistic object $A$ is intuitionistically determined (or understood) if we have laid down what constructions constitute a proof of $A$, i.e., if we have a construction $r_{A}$ such that, for any construction $c$, $r_{A}(c)=0$ if $c$ is a proof of $A$ and $r_{A}(c)=1$ if $c$ is not a proof of $A$ : the logical particles in this explanation are interpreted truth functionally, since we are adopting the basic intuitionistic idealization that we recognize a proof when we see one, and so $r_{A}$ is decidable.

...

As Heyting indicated, one then obtains proof conditions for $A$. . In particular, if $A$ is $B \circ C$, where $\circ$ denotes a logical connective and $r_{B}$ and $r_{C}$ determine the sense of $B$ and $C$, then we obtain $r_{A}$ from $r_{B}$ and $r_{C}$.

Kreisel (1962, pp. 201-202)

In his second version (1965) Kreisel offers some further comments as to the basic set-up of his theory of constructions:

Proofs of What? If the logical operations, in terms of which the usual operations are built up, are not primitive but explained, then the basic proofs must be proofs of special assertions in which the (problematic) logical operations are not involved. One such kind is familiar from quantifier-free mathematics, for example, quantifier-free arithmetic, which consists of assertions $A(n)$ for decidable numerical properties $A(n)$. In intuitionistic mathematics this is generalized. Instead of numbers, we have arbitrary mathematical objects, that is (ideas of) concrete objects and constructions; instead of numerical properties, we have notions, that is, understood, decidable properties of mathematical objects. A notion is denoted by a symbol $v$, and $v(a)=0$ if the object $a$ has $v, v(a)=1$ otherwise; for example, the property of being a finite sequence is a notion. Since notions are decidable, the usual truth functional operations may be applied to equations $v(a)=0, v(a)=1$

A fundamental Principle ... The meaning of $p$ is a proof of $v(a)=0$ for all $a$, is understood for notions $v$; in other words, we recognize a proof af an assertion of this form when we see one.

Kreisel (1965, pp. 123-124)

Kreisel's actual formulation of the theory of constructions using the above concepts is very formalistic, and a more accessible presentation of the Kreisel theory can be found in Troelstra (1969, Section 2). Some features of Kreisel's formalism have also become part of standard expositions of Heyting's explanations. Cf. the following quote from van Dalen (1979, pp. 133-134):

a proof $p$ of $A \wedge B$ is a pair of proofs $p_{1}, p_{2}$ such that $p_{1}$ proves $A$ and $p_{2}$ proves $B$, a proof $p$ of $A \vee B$ consists of a construction which selects one of the formulas $A$ and

$B$ and yields a proof for that particular formula,

a proof $p$ of $A \rightarrow B$ is a construction which assigns to each proof $q$ of $A$ a proof $p(q)$ of

$B$, plus a verification that $p$ indeed satisfies these conditions, 
a proof $p$ of $\neg A$ is a proof of $A \rightarrow 1$, where $\perp$ is some contradiction,

a proof $p$ of $\forall x A(x)$ is a construction which assigns to each object $a$ (of the domain of discourse) a proof $p(a)$ of $A(a)$, plus a verification that $p$ indeed satisfies these conditions,

a proof $p$ of $\exists x A(a)$ is a construction which selects an object $a$ (of the domain of discouse) and yields a proof of $A(\bar{a})$. $\ldots$

The hard cases are here, and in most interpretations, implication (negation) and universal quantification. In the case of implication we are faced with a construction which operates on construction [Sic!] (so possibly on itself), which lends an impredicative character to the whole interpretation.

Kreisel used

for the relation

$$
\Pi(c, A)
$$

construction $c$ proves proposition $A .^{1}$

Using this notation we may state some salient features of Kreisel's theory:

$$
\Pi(c, A) \text { is a decidable mathematical predication }
$$

There are second clauses in the explanation for implication and universal quantification to the effect that one construction is proved by another to do what it is supposed to do.

If $A$ is a mathematical proposition, then so are $\Pi(c, A)$ and $\Pi(d, \Pi(c, A))$, etc., etc.

In a certain sense, features (2) and (3) are consequences of (1). Kreisel wished to explain the logical operations in a reductive way, without having to use these same operations in the explanations. His unproblematic propositions were, as we saw above, quantifier-free general identities for which the desired decidability is granted. The explanations of more complex propositions then have to be given in such a way that simple properties of the constructions permit the derivation of the decidability of the II-predicate also for the more complex propositions. It is in this context that the second clauses $^{2}$ are needed to ensure that the decidability can be carried over also to implicational and universally quantified propositions. On the other hand, if $\Pi$ is a decidable mathematical predicate, then the result of applying $\Pi$ to a construction $c$ and proposition $A$ is again a mathematical proposition, which can serve as an argument for the II-predicate, and so on.

This view of construction, proofs and propositions has become standard 
in expositions of intuitionism, and one finds Heyting's explanations set out, roughly as in the quote from van Dalen (1979), in many places, e.g., Myhill $(1967,1968)$, Toelstra $(1969,1977)$, van Dalen $(1973,1979)$ and Goodman (1970). Dummett (1963, p. 153;1969, p. 361; 1976, p. 110;1977, pp. 12, $320,399,400 ; 1980$, p. 13) has been a firm advocate of the decidability of the proof relation. Feferman (1979) preserves features (2) and (3), but remains uncommitted as to (1). Beeson (1979), however, explicitly rejects (1) and retains (2) and (3). Both positions appear somewhat lacking in motivation: the second clauses were after all put in so as to guarantee decidability.

Peter Aczel observed that maybe one ought to include a fourth (tacit) component in the description of the Kreisel theory, viz.

$$
\text { There is a universe to which everything belongs. }
$$

No such principle is stated by Kreisel, but it seems to follow from some of the other features of his theory. In (3) the proof predicate is viewed as an ordinary mathematical predicate on par with, say, " . . divides . . ." or “. . is a prime." This is particularly obvious from Myhill's (1968, p. 327) and Beeson's ready affirmation of the

basic constructive tenet...

(for all meaningful assertions $\phi$ )...

(A-P) To assert is to prove: $\phi \leftrightarrow \exists p$ ( $p$ is a proof of $\phi$ )

Beesson (1981, p. 5)

Here, if " . . $4 r .$. " is taken to be what it usually is, viz. a propositional connective, both " . . " and "..." have to be filled with propositions. So $\exists p(p$ is a proof of $\phi)$ must be a propostion. But this presupposes some universe over which the existential quantifier ranges and over which " $\ldots$ is a proof of ..." is a predicate. Hence, on this way of looking (4), it also is a consequence of (3) (and so, ultimately, of (1)). On the other hand, one can also suggest a way to start with (4) and obtain (1) as a consequence: If the universe is thought of as a structure (in a model theoretic sense) it would appear determinate over this structure, 'for all meaningful assertions $\phi$ ' and constructions $c$, whether $c$ proves $\phi$ or not. Feature (4) appears quite natural when one considers Kreisel's aim in his original presentation of the theory: he wished to set up an abstract theory of proofs (constructions) such that the logical constants could be defined and their properties derived within the logic-free theory of constructions. We may compare his 
programme with a common interpretation of the logicist programme:

(a) to define mathematical concepts in terms of logic, and

(b) to derive the mathematical theorems as truth of logic.

The parallel is obvious:

(a') to define the logical constants in terms of constructions, and

(b') to derive the truths of logic as theorems of the theory of constructions. $^{3}$

The universe in (4) is then the universe of the theory of constructions, which is viewed as a mathematical formal theory. In the case of classical mathematics the universe in question would be the set theoretic universe.

As to (1), Professor Kreisel informed $\mathrm{me}^{4}$ that a main motivation was the primitive recursiveness of the numerical predicate " $x$ is the Gödel number of a derivation (in system $S$ ) of the wff with number $y . " 5$ The philosophical justification of (1), i.e., that 'we recognize a proof when we see one' has a strong Wittgensteinian flavour. Cf. the following list:

II: 1 'A mathematical proof must be perspicous' ... It must be possible to decide with certainty whether we really have the same proof twice over, or not.

II: 22 "A proof must be capable of being taken in"...

II: $28 \quad \ldots$ the proof must convince us of the proposition ...

II: 39 . . when we say in a proof: This must come out - then this is not for reasons that we do not see...

II: 42 ... Proof must be a procedure plain to view ...

Wittgenstein (1956)

It is not difficult to conceive of an entry:

We recognize a proof when we see one

in the above list. ${ }^{6}$

\section{H.EYTING IN PERSPECTIVE}

As is now fairly well-known, (1956) was not the first place where Heyting treated of the meaning of the logical constants. Already in the early 1930's he began to wrestle with this problem: 
L'affirmation. - Une proposition p, comme, par example, "la constante d'Euler, est rationelle"; exprime une problème, ou mieux encore une certaine attente (celle de trouver deux entiers $a$ en $b$ tels que $C=a / b$ ), qui pourra être réalisée ou décue.

...

Remarquons encore que, en logique classique comme en logique intuitionniste, l'affirmation d'une proposition n'est pas elle-même une proposition, mais la constation d'une fait.

Heyting (1930, pp. 958--959)

In this paper Heyting leaves it open whether all mathematical propositions express problems (or expectation) in the same way as "Euler's constant is rational" (cf. the discussion on the difference between $p$ and $+p$ on p. 961).

It is interesting to note that already in his first treatment of the question Heyting notes the connection between propositions and problems. Also the second part of the above quote is an important insight: the assertion of a proposition is not itself a proposition.

Both points were iterated in the famous Köningsberg address:

Ich unterscheide zwischen Aussagen und Sätzen: ein Satz is die Behauptung einer Aussage. Eine mathematische Aussage drïckt eine bestimmte Erwartung aus; z.B. bedeutet die Aussage "Die Eulersche Konstante $C$ ist rational" die Erwartung, man könne zwei ganze Zahlen $a$ und $b$ finden, derart, dass $C=a / b$. Vielleicht noch besser als das Wort "Erwartung" drïckt das von den Phänonmenologen geprägte Wort "Intention" aus, was hier gemeint wird. Ich gebrauche das Wordt "Aussage" auch für die durch die Aussage sprachlich zum Ausdruck gebrachte Intention. Die Intention geht, wie schon früher betont, nicht auf einen also unabhängig von uns bestehend gedachten Sachverhalt, sondern auf ein als möglich gedachtes Erlebnis, wie es auch aus dem obigen Beispiel deutlich hervorgeht.

Die Behauptung einer Aussage bedeutet die Erfillung der Intention, z.B. wïrde die Behauptung " $C$ ist rational" bedeuten, man habe die gesuchten ganzen Zahlen tatsächlich gefunden. Ich unterscheide die Behauptung von der entsprechenden Aussage durch das Behauptungszeichen $\vdash$ das von Frege herrührt und auch von Russell und Whitehead zu diesem Zweck gebraucht wird. Die behauptung einer Aussage ist selbst wieder nicht eine Aussage, sondern die Feststellung einer empirischen Tatsache, nämlich der Erfüllung der durch die Aussage ausgedrückten Intention.

...

Ich schliesse mit einigen Bemerkungen über die Frage nach der Lösbarkeit mathematischer Probleme. Ein Problem ist gegeben durch eine Intention, deren Erfüllung gesucht wird. Es ist gelöst, wenn entweder die Intention durch eine Konstruktion erfüllt ist oder bewiesen ist, dass sie auf einen Widerspruch führt. Die Lösbarkeitsfrage kann also auf die Beweisbarkeitsfrage zurïckgefihrt werden.

Heyting (1931, pp. 113-114)

In the Köningsberg paper he is still undecided as to whether every proposition involves a construction and the $p /+p$ difference is again alluded 
to. Somewhat later he withdraws the $p /+p$ considerations - they were 'nicht stichhaltig" (1934, p. 16). Now he finally commits himself:

Jede mathematische Aussage steht nach HEYTING für die Intention auf einen mathematische Konstruktion, die bestimmten Bedingungen genügen soll. Ein Beweis für eine Aussage besteht in der Verwirklichung der in ihr geforderten Konstruktion. $a \supset b$ bedeutet dann die Intention auf eine Konstruktion, die aus jedem Beweis für $a$ zu einem Beweis für $b$ führt. Einen verwandten Gedanken, der insoweit über den vorigen hinausgeht, dass er dem HEYTINGschen Kalkul auch unabhängig von intuitionistischen Voraussetzungen einen Sinn verleiht, hat KOLMOGOROFF [1] angegeben. Er deutet den Kalkul als Aufgebenrechnung. Jede Verändeliche steht für eine Aufgabe; diesen Begriff erklärt er nicht; man kann ihn wohl interpretieren als die Forderung, eine mathematische Konstruktion die gewissen Bedingungen genügt, anzugeben.

Heyting $(1934, \text { p. } 14)^{8}$

He also makes the point about assertion and proposition, now reformulated in terms of the problem-view of propositions:

Dass eine Aufgabe gelöst ist, wird angegeben, indem man das Zeichen † davor setzt; eine Formel, die diese Zeichen enthält, stellt keine Aufgabe mehr dar, sondern eine Mitteilung über die Lösung einer Aufgabe.

Heyting (1934, p. 14)

This is perhaps the place to treat of the connections between the respective view of Heyting and Kolmogoroff. Kolmogoroff (1932) proposed to interpret the letters of Heyting's propositional calculus as 'problems', and problems he individuated in terms of their solutions. Already in Heyting (1931) it was noted that the problem-explanation could be subsumed under the view that propositions express intentions towards constructions, where in order to solve the problem one has to prove a corresponding proposition by carrying out such a construction as intended in the proposition. This remark can be made a bit more precise. With a mathematical proposition $A$ in the sense of Heyting (1934) - hence all propositions essentially involve constructions - we associate a problem $P_{A}$, which is to be solved by carrying out a construction as intended by $A$, and with each problem $P$ we associate a proposition $A_{P}$ by letting $A_{P}$ express the intention towards constructions which solve $P$. Then the following two claims hold: $A$ and $A_{P_{A}}$ are the same proposition, i.e., express the same intensions

and $P$ and $P_{A_{P}}$ are the same problem, i.e., have the same solutions. 
Let us verify the latter. Consider a solution to the problem $P$. Such a construction would also serve to prove the proposition $A_{P}$, because $A_{P}$ expresses an intention towards a construction which is a solution of $P$. But then the construction must also be a solution to the problem $P_{A_{P}}$ because these are the constructions intended by $A_{P}$. On the other hand, consider a solution of $P_{A_{P}}$. This solution must serve to fulfil the intention expressed by $A_{P}$, but by the explanation of $A_{P}$, the constructions which serve to fulfil this intention are precisely the solutions of the problem $P$. The argument just given is readily modified so as to verify (i) as well. ${ }^{10}$ Hence the two explanations offered by Heyting and Kolmogoroff, that propositions express intentions towards constructions, or that they pose problems which are solved by carrying out constructions, really amount to the same thing. It is important to notice that Heyting and Kolmogoroff are not giving interpretations in the contemporary sense of reinterpretation (or reformulation) of mathematical propositions. Examples of the latter are Kleene's (1945) realizability and Gödel's Dialectica-interpretation. In such interpretations, with each proposition $A$ one associates another proposition $A^{*}$, e.g., ' $A$ is realizable', and it makes perfect sense to inquire as to the truth of the mathematical proposition

$$
A \leftrightarrow A^{*} \text {. }
$$

Thre is no attempt in such interpretations to explain the meaning of the propositions but instead one uses the propositions. If we were to ask the same question for the Heyting-Kolmogoroff explanation the result is a piece of nonsense like:

$$
A \leftrightarrow \text { the explanation of } A .
$$

This is nonsense because the propositional connective $\leftrightarrow$ needs to be filled with propositions and the right-hand side is not a proposition (in use), but a meaning-explanation of a proposition. On the left-hand side, on the other hand, we do have a proposition in ordinary use and not an explanation. Heyting and Kolmogoroff do not give mathematical reformulations but try to explain what propositions are; theirs is not a mathematical activity but a philosophical one. Cf. van Dalen (1979, p. 135):

Both Heyting and Kolmogoroff's interpretation [Sic!] were fundamental in nature, i.e., they were intended as the "true" meaning of intuitionistic logic. Of the two, clearly Heyting's interpretation is foundationally the more important one. 
I would prefer "explanations" in place of "interpretation" in the first sentence of this quote, but otherwise 1 agree with van Dalen. Given the essential equivalence of the two explanations, the second part seems less correct, however; Heyting himself also came to see that his was not a different explanation from that of Kolmogoroff:

The older interpretations by Kolmogoroff (as a calculus of problems) and Heyting (as a calculus of intended construction) were substantially equivalent.

Heyting (1958, p. 107)

The difference in aims between the early views of Heyting-Kolmogoroff and Kreisel now become clear. Heyting-Kolmogoroff do not give a reduction to any other theory, but try to explain what a proposition is, how it should be understood. For Kreisel, on the other hand, the aim was to formalize the properties of the 'abstract constructions' in a theory and reduce the theory of logic to that. Kreisel is thus closer to the interpretations just mentioned, e.g., Gödel's Dialectica and the realizability interpretations.

Although we shall have occasion to return to the writings of Heyting, let us summarize a few of his views as we have found them up till now.

H1. A mathematical proposition is proved by carrying out a certain construction (which must satisfy certain properties such as giving a certain object).

e.g. in the example of "Euler's constant is rational" the appropriate object would be a pair of objects.

H2. The meaning of a proposition is explained in terms of what constructions have to be carried out in order to prove the proposition.

H3. The assertion of a proposition is not itself a proposition, i.e., the fulfilment of the intention expressed by the proposition through the carrying out of a certain construction is not a proposition. Also, then, the "assertion-condition" on constructions (construed as a property of constructions) is not propositional in nature.

What then is a theorem, on Heyting's view? "Every theorem has the form (if enunciated without abbreviations): 'A construction with such and such properties has been effected by a mathematician'." 11 But we know that for Heyting to carry out a construction with such and such properties is to 
prove a proposition, namely one which expresses an intention towards constructions with such and such properties. So it is not the proposition itself which is the theorem, but that is has been proved. One can reformulate Heyting's dictum in the (for him) equivalent form:

H4. Every theorem has the form: "A proposition has been proved". ${ }^{12}$

or, equivalently,

H4 A mathematical theorem has the form:

Construction $C$ has been carried out, producing object $c$, thereby $\left\{\begin{array}{l}\text { proving proposition } A \text {. } \\ \text { fulfilling the intention expressed by } A \text {. }\end{array}\right.$

Let us finally note that there are no second clauses in Heyting's own formulations of his explanations for $\rightarrow$ and $\forall$. In (1934) and (1956) there are none, and so as not to try the reader's patience with a long retrospective list of quotes, I will confine myself to one further, late, statement:

I may assert $A \rightarrow B$ when I am able to convert any proof of $A$ into a proof of $B$. In other words, I must possess a general method of construction which, when applied to proofs of $A$ yields a proof of $B$.

Heyting (1974, p. 87)

The only place I have found where Heyting even mentions the second clauses is (1968, p. 318), but then only in the process of describing the contribution of Kreisel $(1962,1965)$ as a part of a general survey of recent work within intuitionism. ${ }^{13}$

\section{THE RELATION BETWEEN CONSTRUCTIONS AND PROOFS}

In this section I will consider some theses on the concepts mentioned in the title of this paper, and on some of their inter-relations.

(I) Mathematical propositions are seen to be true - may be asserted - by being proved.

This seems a fairly uncontroversial principle (even from a classical point of view).

(II) We recognize a proof when we see one. 
There is something intuitively right about this; part of the same intuition seems to be that a proof determines its conclusion. ${ }^{14}$ One must be able to understand the proof as a proof, and what it proves, in order that it be a proof.

(III) Proofs begin with immediate truths (axioms), which themselves are not justified further by proof, and continue with steps of immediate inference, each of which cannot be further justified by proof.

This is a formulation of Aristotle's conception of organized knowledge.

The assertion of a proposition is not itself a proposition.

This is a difficult principle which one can hardly reconcile with current metamathematical conceptions of logic. ${ }^{15}$ The early logicians - Frege, Russell-Whitehead, Heyting - were quite strict in their observation of this point. The main change occurs around 1930 with the triumph of metamathematics, after which point the turnstile takes on the meaning of a derivability-predicate, i.e., a predicate operating on strings of symbols indicating that a certain inductively generated tree of strings of symbols exists, rather than a force indicator as in Frege and Russell.

The meaning of a proposition is determined by how it may be proved.

If (V) is combined with Fregean compositionality, i.e., that the meaning of a complex proposition should be functionally dependent on the meaning of its relevant constituents, we obtain that the meaning is given uniformly in terms of its assertion condition, and hence, as was already noted, as the assertion condition is not propositional, the key-concept in the meaning explanations is not propositional. This emphasizes a difference with the (propositional) Kreisel theory and Heyting's explanations. Heyting does not give a reduction to a more simple theory. Here one can draw a parallel with Frege: If the meaning is to be explained in terms of $\Pi$, then the regress in (3) would be a vicious one and formally similar to the one Frege runs for truth in the opening sections of (1918). ${ }^{16}$ We should also note that if $(V)$ is supplemented with compositionality one would expect the theory of constructions (not necessarily Kreisel's) qua theory of meaning to operate 
with two inter-related notions, namely

and

$$
A \text { is a proposition }
$$

$$
\Pi(c, A) \quad \text { (i.e., the assertion condition for } A \text { ). }
$$

("inter-related" in the sense that claims of the form' $A$ is a proposition' may depend on $\Pi(c, B): s$ for constituents $B$ of $A$.)

(VI) Proofs are constructions.

There is no question but that this is a basic feature of Heyting's view. Already at the outset we find:

Ein Beweis für eine Aussage ist eine mathematische Konstruktion, welche selbst wieder mathematisch betrachtet werden kann.

Heyting (1931, p. 114)

The rider concerning the possibility of regarding the proof construction as a mathematical object in its own right shows that Heyting here, in so far as this issue is concerned, is speaking as an intuitionist, by which term I understand, not a general adherent of "constructivism", but more specifically an intuitionist in Brouwer's sense. I would like to calim that the "theories of constructions" when considered as theories of meaning cannot find their place within Brouwerian intuitionism. As a consequence I would also hold that it is misleading to think in terms of the equation:

$$
\begin{aligned}
& \text { Intuitionism = Basic constructivism }+ \text { choice sequences }+ \\
& \text { continuity. }{ }^{17}
\end{aligned}
$$

Indeed, when the theories of constructions are given their meaningexplanatory role the separation will immediately arise between the mathematical activity reported in the constructivist language and the meaning-explanations in the secondary reflective activity. Now for Brouwer, as witnessed by his philosophical writings (1929) and (1948), mathematical reflection (reflection on the mathematical activity) is itself a part of mathematics: the secondary activity is included in the first. A nice example of this is given in the remarkable self-reflexivity of his proof of the Bar-theorem. An immediate consequence of such a view on the primary and secondary activities would be that meaning-theoretical considerations are ruled out; as soon as we have a language there arise questions of meaning over that language. Therefore Brouwer's first act of intuitionism seems inevitable within his framework: 
Completely separating mathematics from mathematical language and hence from the phenomena described by theoretical logic, recognizing that intuitionistic mathematics is an essentially languageless activity of the mind ...

Brouwer (1981, p. 4)

The use of language forces the separation of activity and reflection over that activity, but for Brouwer activity and reflection are one. So the activity must be essentially languageless.

Such, then, are my reasons for finding it mesleading to view intuitionism as an "extension" of basic constructivism. This view seems supported by the fact that Heyting does not give semantical explanations of typically intuitionist concepts, like infinitely proceding sequence and spread, together with his explanations for the logical constants. Thus there seems to be a discrepancy between Heyting, the semanticist of constructivism, and Heyting, the Brouwerian intuitionist. In the quote above on constructions and proofs he wishes to have it both ways, it appears. This, however, is not possible, as soon as the meaning-explanatory aspects are taken into account.

(VII) Constructions are mathematical objects.

Theses (VI) and (VII) taken together imply that proofs are (presumably abstract) objects, i.e., the starting point of the Kreisel theory of constructions. Note how readily some features of the Kreisel theory result from the theses above. By (VI), (VII) proofs are objects and by (II) we recognize a proof when we see one and so the relation between proof-object and proposition is decidable. However, this relation would appear to be mathematical in nature (as the proofs are mathematical objects) and then one gets into difficulties with theses (IV) and (V): the assertion condition is not (mathematical) propositional. Perhaps the solution to this riddle lies in the fact that the word

\section{construction}

is ambiguous. ${ }^{18}$ It can mean, among other things:

(a) process of construction

(b) object obtained as the result of a process of construction

(c) construction-process as object (rather than as something "dynamic"). 
My suggestion is then that "construction" occurs with different senses in the theses (VI) and (VII). In (VII) the notion of construction seems to be that of (b) and in (VI) that of (a). In particular I would also suggest that the $c$ in $\Pi(c, A)$ ought, if one wishes to keep the meaning-theoretical aims, to be taken in the sense (b). (Kreisel in his theory of abstract proofs seems to use (c)).

With these distinctions $\mathrm{H} 4$ from our summary of Heyting's position can be reformulated yet another time:

H4". A mathematical theorem has the form:

Construction (process) $C$ has been carried out, producing (construction) object $c$, thereby proving proposition $A$.

Brouwer's notion of construction seems to be none of the above. Perhaps an amalgam of (a) and (c) gives something which can serve as a model for an outsider? In the mathematical activity one carries out (processes of) constructions, but in reflection on these (which is also a part of the mathematical activity) one can treat the processes as objects. ${ }^{19}$

For Heyting the important notion seems to be (a):

So wird jede allgemeine Konstruktionsmethode $z \mathfrak{u}$ einer bedingten Konstruktion, das heisst, zu einer Konstruktion $A$, die erst ausgeführt werden kann, wenn gewisse andere Konstruktionen $B$, die vorgegebenen Bedingungen genügen sollen, ausgefuihrt sind.

Heyting (1958a, p. 334)

In Heyting (1960, p. 180) we find a list of construction methods:

I: construction d'un nombre naturel,

II: construction hypothétique,

III: methode générale de construction,

IV: contradiction.

Let us consider a very elementary example in order to indicate how this can be understood. (We use $p$ and $q$ for left and right projections on pairs of objects.)

On the assumption $\Pi(x, A \& B)$, then clearly $\Pi(x, A \& B)$. But such an $x$ must be a pair with certain properties. Hence, still on the same assumption, $\Pi(p(x), A)$, and, therefore, outright on no assumptions, $\Pi(\lambda x p(x)$, $A \& B \rightarrow A)$. This can be represented in tree form: 


$$
\begin{array}{ll}
\frac{\Pi(x, A \& B)}{\Pi(p(x), A)} & (\Pi(x, A \& B)) \\
\frac{\Pi(\lambda x p(x), A \& B \rightarrow A)}{(\Pi(x, A \& B))}
\end{array}
$$

(where we have indicated dependence on possible assumptions to the right of each line). The proof of the proposition $A \& B \rightarrow A$ is given by the whole tree, with its conclusions $\Pi(\lambda x p(x), A \& B \rightarrow A)$, and the whole tree represents the construction (process) of the construction (object) $\lambda x p(x)$. That this object (this function, this construction) has such and such properties is guaranteed by the way it is constructed. The constructions which occur in the second clauses are of the sort (a), whereas in the first caluse of the implication-explanation the construction is of the sort (b). In order to prove any proposition ${ }^{20}$ one always has to exhibit a construction (object) of sort (b), which must satisfy certain properties. These are guaranteed to hold by means of the construction (process) of sort (a). (Indeed, one should, given thesis (IV), not expect that $\Pi(c, A)$ would be proved by a construction of the same sort as $c$.) If we refer back to $\mathrm{H} 4$ " the tree above fits very well with the formulation given there: the construction $C$, which has been carried out, is given by the whole tree and the object $c$ which has been obtained as the end-result is $\lambda x p(x)$, while the proposition proved is $A \& B \rightarrow A$. The example just considered exemplifies II on Heyting's list: hypothetical construction. Similar examples can be given also for the other methods of construction there.

There now remains to check how the theses (I) to (V) tally with the process/object distinction for constructions. Thesis (I) I take to refer to proofs as construction-processes giving certain construction-objects: mathematical propositions are seen to be true by carrying out a construction-process giving a construction-object of a certain sort. Thesis (II) can be understood in two ways: (a) that when we "see" a construction process - when we have "taken in" the construction process - we understand it as a proof of some proposition, or (b), when we see a construction object, as a result of a process, then we understand that it is of the right sort simply from the way it is the result of the process. Both readings are, I think, quite natural. That the proof determines its conclusion is one way of saying that the sort of object produced is determined by the process of construction. The Aristotelean (III) simply says that construction processes are put together form basic construction steps and must begin with something. 
In thesis (IV), on the present reading, what gets said is that, that the construction-object, which is produced by a construction-process, is of the right sort for a proposition, is not itself a proposition and does not express an intention towards yet another construction-process; that the process produces such an object is not a proposition. Similarly in (V), the meaning is determined by what processes have to be carried out in order to prove the proposition. The theses (VI) and (VII) have already been dealt with.

\section{FORMAL WORK ON THE THEORY OF CONSTRUCTIONS}

To the best of my knowledge only two out of existing formal systems for "theories of constructions" respect the difference between constructions as processes and as objects, viz. Scott's system in his (1970) and the various versions of the type theory of Martin-Löf $(1975,1975 \mathrm{a}, 1970)$. These systems were developed in the late 1960's and were, on the technical side, inspired by Kleene's (1945) notion of realizability, and Läuchli's (1970) abstract version thereof. Other very important sources of inspiration were Gödel's Dialectica translation and Howead's notion of "formulae-as-type", cf. Howard (1980). The system AUTOMATH of de Bruijn - an up to date survey is in de Bruijn (1980) - also influenced the work.

Scott, in particular, emphatically stressed the point to which this paper has been mainly devoted:

(iii) We have no abstract proofs, only constructions and species of constructions. When the author finally obtained his formalism the proofsas-object [i.e., processes-as-objects in the terminology of the present paper. G.S.] vanished.

Scott (1970, p. 241)

and

Take implication first ... what must be done in order to establish $A \supset B$ ? One must first produce a construction (object G.S.) together with a proof (process of construction G.S.) that this construction transforms every construction that could establish $A$ into a construction for $B$. The construction is an object of the theory while the proof is an elementary argument about the theory.

Scott (1970,pp. 261-262)

Unfortunately Scott gave up the project and in a post scriptum he says that he has been convinced by Kreisel and Gödel of the need for abstract proofs (as objects). Be that as it may; the system of Scott, by the side of the more 
elaborated theories and meaning-explanations of Martin-Löf, is the closest system we have got for a theory of construction qua theory of meaning for the constructive logical constants. Recently a fair number of formal systems have been proposed for diverse theories of constructions. This being so, and given that the present paper has dealt with his theory at some length, it seems fair to let Kreisel get the last word with the following appropriate observation that

work directly concerned with the intended meaning of intuitionistic formal systems is not at all essentially mathematical.

Kreisel (1973, p. 262)

\section{NOTES}

The research reported herein was supported by a Fellowship by Examination at Magdalen College, Oxford. It was begun when I was a Visiting Lecturer at Utrecht, Spring 1980, as a reaction to Beeson's 1979 , and I am grateful to him, van Dalen and Visser for almost daily opposition. The paper has been presented at Stockholm, Manchester, Oxford, Münster and Oberwohlfach and I have benefitted from comments by participants in those seminars and Peter Aczel in particular. Professors Kreisel and Martin-Löf, as well as the Editor offered detailed and constructive comments on a preliminary version.

1 The relation $\Pi$ is not basic for Kreisel, who instead uses ' $\pi(c, a, b)=0$ ' (1962, p. 202 and p. 206, REMARK). His followers, who sometimes have put the formal theories of Kreisel to a use they were not made for (see below), have usually used the informal counterpart to $I I$ in their expositions of Hey ting's scheme (rather than $\pi$ ).

3 As far as I have been able to make out, the second clauses make their entry in footnote 4 of Kreisel (1961, p. 107).

${ }^{3}$ Kreisel draws an analogous parallel, cf. the reference in footnote 2, as well as (1962, Section 2). In a letter of 6.1.82, Prof. Kreisel draws my attention to his review Zentralblatt 199, p. 300 where he questions the interest of the whole project of developing an abstract theory of proofs.

4 At the Brouwer-conference, Noordwijkerhout, June 1981.

5 Kreisel had applied this idea to his earlier work on the progressions, see (1962, p. 207, footnote 10 ).

6 Prof. Kreisel was not aware of a direct influence from Wittgenstein (cf. footnote 4), but see Kreisel (1958).

7 This is a point which goes back at least to Frege. For him the turnstile, composed of two parts - the content and judgement strokes, respectively - was an indicator of assertoric force and not, as is the case today, a metamathematical symbol meaning "is derivable". Bell (1979, pp. 97-98) is a good reference here cf. also Dummett (1973, Chapter 10).

KOLMOGOROFF [1] = Kolmogoroff (1932).

9 Troelstra (1981) contains interesting information about Heyting's early views, and, in particular, about his contact with Kolmogoroff. 
10 I am indebted to Martin-Löf for the above view on the relation between propositions and problems.

${ }^{11}$ Heyting (1958b, p. 278).

12 Standard formal systems, e.g., HA - Heyting Arithmetic - do not seem suitable to represent this notion of theorem. If the wffs are intended to represent propositions and derivable objects the theorems, then the theorems are propositions, whereas for Heyting the theorem is that a proposition has been proved. Kreisel asked the pertinent question: 'Was the (logical) language of the current intuitionistic systems obtained by uncritical transfer from languages which were, tacitly, understood classically?' (1973, p. 268).

${ }_{13}$ Professor Troelstra stresses (in conversation) that one cannot conclude that Heyting rejected the second clauses from the fact that they never appear in his work. That is so, but as they never appear and from the fact that he never endorsed them, it seems that at least one ought not to put the name of Heyting on formulations which include them.

14 Remember the analogy with the derivation predicate of Gödel-numbers; also there the conclusion Gödel number can be read off primitive recursively from the derivation Gödel number.

15 See Note 12 above.

16 There are some prima facie difficulties with the view that meaning is determined by proof, or assertion, conditions:

(a) one can do too much it seems, cf. Prior's "TONK".

(b) the paradox of inference - how can logic be both valid and useful - seems to threaten, cf. Dummett (1973a).

(c) if the meaning of a proposition is explained in terms of proof, can one then only understand proved propositions?

These difficulties will be discussed in detail in detail in my "Meaning Theory and Proof", forthcoming in "A Handbook of Philosophical Logic" (Eds. Gabbay and Guenthner).

17 Beeson (1981a, p. 148) uses a more formalistic version of this equation to characterize intuitionism.

${ }^{18}$ Mutatis mutandis, in most European languages.

19 See Brouwer (1929) and (1948).

${ }^{20}$ And not just those of implication form: there is nothing special about implication.

\section{B I B L I OG R A P H Y}

Beeson, M., A Theory of Constructions and Proofs, Preprint No. 134, Dept. of Mathematics, Univ. of Utrecht (1979).

Beeson, M., Problematic Principles in Constructive Mathematics, Preprint No. 185, Dept. of Mathematics, Univ. of Utrecht (1981).

Beeson, M., 'Formalizing Constructive Mathematics: Why and how?', in Richman, E. (ed.), Constructive Mathematics, Lecture Notes in Mathematics, Vol. 873, pp. 146-190, Springer, Berlin (1981a).

Bell, D. Frege's Theory of Judgement, Clarendon Press, Oxford (1979).

Brouwer, L. E. J., 'Mathematik, Wissenschaft, Sprache', Monatshefte f. Mathematik und Physik 36 (1929), 153-164. 
Brouwer, L. E. J., 'Consciousness, Philosophy and Mathematics', in Proc. Xth Intern. Congress Philosophy, pp. 1235-1249, North-Holland, Amsterdam (1948).

Brouwer, L. E. J., Brouwer's Cambridge Lectures on Intuitionism, v. Dalen (ed.), C.U.P., Cambridge (1981).

de Bruijn, N. G., 'A Survey of the Project AUTOMATH', in Seldin and Hindley (eds.), To H. B. Curry: Essays on Combinatory Logic, Lambda Calculus and Formalism, pp. 579-606, Academic Press, London (1980).

van Dalen, D., 'Lectures on Intuitionism', in Mathias, A. D. and Rogers, H. (eds.), Cambridge Summer School in Mathematical Logic, pp. 1-94, Lecture Notes in Mathematics 337, Springer, Berlin (1973).

van Dalen, D., 'Interpreting Intuitionistic Logic', in Baayer, v. Dulst and Oosterhoof (eds.), Proc. Bicentenical Congress Wiskundig Genootschap, Vol. I, pp. 133-148, Mathematical Centre Tracts 100, Mathematisch Centrum, Amsterdam (1979).

Dummett, M., 'The Philosophical Singnificance of Gödel's Theorem', in TE, pp. 186-201 (1963). Also published in Ratio V (1963), 140-155.

Dummett, M., 'The Reality of the Past', in TE, pp. 358-374 (1969).

Dummett, M., Frege, Duckworth. London (1973).

Dummett, M., 'The Justification of Deduction', in TE, pp. 290-318 (1973a). Also published in Proc. British Academy, Vol. LIX, 1975, pp. 201-232.

Dummett, M., 'What is a Theory of Meaning? (II)', in Evans and McDowell (eds.), Truth and Meaning, Clarendon Press, Oxford (1976).

Dummett, M., Elements of Intuitionism, Clarendon Press, Oxford (1977).

Dummett, M., 'Comments on Professor Prawitz's Paper', in von Wright (ed.), Logic and Philosophy, pp. 11-18, Nijhoff, The Hague (1980).

TE, Truth and Other Enigmas, Duckworth, London (1978).

Feferman, S., 'Constructive Theories of Functions and Classes', in Boffa, v. Dalen and McAloon (eds.), Logic Colloquim '78, pp. 159-224, North-Holland, Amsterdam (1979).

Frege, G., 'Der Gedanke', Beiträge zur Philosophie des Deutschen Idealismus 1 (1918), $588-77$.

Goodman, N., 'A Theory of Constructions Equivalent to Arithmetic', in Kino, Myhill and Vesley (eds.), Intuitionism and Proof Theory, pp. 101-120, North-Holland, Amsterdam (1970).

Heyting, A., 'Sur la logique intuitioniste', Acad. Royale de Belgique, Bulletin de la classe de Sciences (5), 16 (1930), 957-963.

Heyting, A., 'Die intuitionistische Grundlegung der Mathematik', Erkenntnis 2 (1931), $106-115$.

Heyting, A., Mathematische Grundlagenforschung, Intuitionismus, Beweistheorie, Springer. Berlin (1934).

Hey ting, A., Intuitionism, an Introduction, North-Holland, Amsterdam (1956).

Hey ting, A., 'Intuitionism in Mathematics', in R. Klibansky (ed.), Philosophy in the Mid-century: A Survey, pp. 101-115, La nuova editrice, Firenze (1958).

Heyting, A., 'Blick von den intuitionistischen Warte', Dialectica 12, (1958a) 332-345.

Heyting, A., 'On truth in mathematics', in Verslag van de plechtige viering van het hondervijftigjarig bestaan der Koninklijke Nederlanse Akademie van Wetenschappen met de teksten der bij die gelegenheid gehouden redevoeringen en voordrachten, pp. 227-279, North-Holland, Amsterdam (1958b).

Heyting, A., 'Remarques sur le constructivisme', Logique et Analyse 3 (1960), 177-182. 
Heyting, A., 'Intuitionism in Mathematics', in R. Klibansky (ed.), Contemporary Philosophy. A survey I Logic and Foundations of Mathematics, pp. 316-323, La Nuova Italia editrice, Firenze (1968).

Heyting, A., 'Intuitionistic Views on the Nature of Mathematics', Synthese 27 (1974), 79-91.

Howard, W. A., 'The Formulae-as-types Notion of Construction', in Seldin and Hindley (eds.), To H. B. Curry: Essays on Combinatory Logic, Lambda Calculus and Formalism, pp. 479-490, Academic Press, London (1980).

Kleene, S. C., 'On the Interpretation of Intuitionistic Number Theory', Journal of Symbolic Logic 10 (1945), 109-124.

Kolmogoroff, A., 'Zur Deutung der Intuitionistischen Logik', Math. Zeitschr. 35 (1932), 58-65.

Kreisel, G., 'Essay-review of Wittgenstein (1956)' British J. Philosophy of Science, Vol. XI (1958), 135-158.

Kreisel, G., 'Set-theoretical Problems Suggested by the Notion of Potential Totality', in Infinitistic Methods, pp. 103-140, Pergamon Press, Oxford (1961).

Kreisel, G., 'Foundations of Intuitionistic Logic', in Nagel, Suppes and Tarski (eds.), Logic, Methodology and Philosophy of Science, pp. 198-210. Stanford Univ. Press, Stanford (1962).

Kreisel, G., 'Mathematical Logic', in Saaty (ed.) Lectures on Modern Mathematics, III, pp. 95-195, Wiley, New York (1965).

Kreisel, G., 'Perspectives in the Philosophy of Pure Mathematics', in Suppes, Henkin, Joja and Moisil (eds.), Logic, Methodology and Philosophy of Science IV, pp. 255-278, North-Holland, Amsterdam (1973).

Läuchli, H., 'An Abstract Notion of Realizability for which Intuitionistic Predicate Calculus is Complete', in Myhill, Kino and Vesley (eds.) Intuitionism and Proof Theory, pp. 227-234, North-Holland, Amsterdam (1970).

Martin-Löf, P., An Intuitionistic Theory of Types; Predicative Part', in Rose and Shepherdson (eds.), Logic Colloquim '73, pp. 73-118, North-Holland, Amsterdam (1975).

Martin-Löf, P., 'About Models for Intuitionistic Type-theories and the Notion of Definitional Equality', in Kanger (ed.), Proc. 3rd Scand. Logic Symp., pp. 81-109. North-Holland, Amsterdam (1975a).

Martin-Löf, P., Constructive Mathematics and Computer Programming, Report No. 11, Dept. of Mathematics, Univ. of Stockholm (1979). Forthcoming in the Proceedings of the VIth Conference for Logic, Methodology and Philosophy of Science.

Myhill, J., 'Notes Towards and Axiomatization of Intuitionistic Analysis', Logique et Analyse 35 (1967), 280-297.

Myhill, J., 'The Formalization of Intuitionism', in R. Klibansky (ed.), Contemporary Philosophy 1; Logic and Foundations of Mathematics, pp. 324-341, La Nuova Italia Editrice, Firenze (1968).

Scott, D. S., 'Constructive Validity', in Symposium on Automatic Demonstration, Lecture Notes in Mathematics 125, pp. 237-275, Springer, Berlin (1970).

Troelstra, A. S. Principles of Intuitionism, Lecture Notes in Mathematics 95, Springer, Berlin (1969).

Troelstra, A. S., 'Aspects of Constructive Mathematics', in Barwise, J. (ed.), Handbook of Mathematical Logic, pp. 973-1052, North-Holland, Amsterdam (1977). 
Troelstra, A. S., 'Arend Heyting and his Contribution to Intuitionism', Niew Archief voor Wiskunde (3), XXIX (1981), 1-23.

Wittgenstein, L., Remarks on the Foundations of Mathematics, Blackwell, Oxford (1956).

Central Interfaculty of Philosophy,

University of Nijmegen,

Postbus 9108,

6500 HK Nïmegen,

The Netherlands 